\title{
ACOUSTICCLASSIFICATION OF FRESHWATER FISH SPECIES USING ARTIFICIAL NEURAL NETWORK: EVALUATION OF THE MODEL PERFORMANCE
}

\author{
Zulkarnaen Fahmi') and Wijopriono' \\ ${ }^{1}$ Researcher at Research Institute for Fisheries Enchancement and Conservation, Purwakarta \\ ${ }^{2}$ Researcher at Research Centre for Fisheries Management and Conservation, Jakarta \\ Received May 07-2012; Received in revised form March 19-2013; Accepted May 14-2013 \\ Email: fahmi_prpt@indo.net.id
}

ABSTRACT:

\begin{abstract}
Hydroacoustic techniques are a valuable tool for the stock assessments of many fish species. Nonetheless, such techniques are limited by problems of species identification. Several methods and techniques have been used in addressing the problem of acoustic identification species and one of them is Artificial Neural Networks (ANNs). In this paper, Back propagation (BP) and Multi Layer Perceptron (MLP) of the Artificial Neural Network were used to classify carp (Cyprinus carpio), tilapia (Oreochromis niloticus), and catfish (Pangasius hypothalmus). Classification was done using a set of descriptors extracted from the acoustic data records, i.e. Volume Back scattering (Sv), Target Strength (TS), Area Back scattering Strength, Skewness, Kurtosis, Depth, Height and Relative altitude. The results showed that the Multi Layer Perceptron approach performed better than the Back propagation. The classification rates was $85.7 \%$ with the multi layer perceptron (MLP) compared to $84.8 \%$ with back propagation (BP) ANN.
\end{abstract}

\section{KEYWORDS: Identification, classification, acoustic descriptors, artificial neural network.}

\section{INTRODUCTION}

Direct species identification is a great challenge in fisheries acoustics. However, species identification has been limited by the difficulty in objectively classifying back scattered energy of echo traces into fish species. It was recognized that working on it is time-consuming and depends on the experience of the operator, incorporating some level of uncertainty or ambiguity. Incorrect species classification and identification can limit the usefulness of acoustic abundance estimates.

Many studies have attempted to develop echotrace classification. First attempts at fish classification introduced basically subjective and timeconsuming methods. These methods involved expert scrutiny of echograms combined with concurrent trawling data. Visual scrutiny of acoustic data depends on human experience and is therefore subject to biases and difficult to be quantified (Charef et al., 2010).

New studies have continually been done and efforts have been devoted to find out methods and techniques for species identification. Recently, Artificial Neural Networks (ANNs) have become the focus of much attention, largely because of these methods are more efficient, timely less or not dependent on subjective interpretation, and controlled by evaluating their accuracy (Jech \& Michaels, 2006), besides their wide range of applicability and the case which they can treat complicated problems. An ANN is a 'black box' approach which has great capacity in predictive modelling, i.e. all the characters describing the unknown situation must be presented to the trained $\mathrm{ANN}$, and the identification (prediction) is then given. Artificial neural networks (ANNs) are non-linear mapping structures based on the function of the human brain.

Muhiddin (2007) applied back propagation of the ANNs to classify sardine in the South China Sea, with a set of acoustic descriptors as input parameters. The classification provided level of accura cyat the rates of $70 \%-100 \%$. Charef et al. (2010) used Multi Layer Perceptron (MLP) of ANNs to identify fish shoals in the South China Sea, showing a performance of classification rates at $87.6 \%$. The discrimination study was done by Robotham et al. (2010) to evaluate performance of Probabilistic Neural Network (PNN) and Support Vector Machine (SVM) against Multi Layer Perceptron (MLP). The study produced the classification rates of $89.5 \%$ against $79.4 \%$.

In Indonesia, some attempts to estimate the freshwater fish populations' biomass were made with acoustic surveys. Hence, selection of models suitable for fresh water fish species classification is crucial for acoustic abundance estimates. In this work, we applied two types of supervised echo-trace classification, Back propagation and Multi Layer Perceptron of artificial neural network (ANNs). This paper describes and evaluates the performance of the 
two models, based on a set of acoustic descriptors to classify three species of freshwater fish, i.e. Tilapia (Oreochromis niloticus), Catfish (Pangasius hypothalmus) and Carp (Cyprinus carpio), which are all important targets for the freshwater fisheries industry.

\section{MATERIALS AND METHODS}

\section{Data Collection}

Acoustic data were collected in January 2011, at Waduk Ir. H. Djuanda, Jatiluhur, in the conical net cage with $0.5 \mathrm{~m}$ mesh size. Scientific Echosounder Simrad EY-60 operated at $120 \mathrm{kHz}$ was used for data acquisition with acoustic target of three species of freshwater fishes, i.e tilapia (Oreochromisniloticus), carp (Cyprinus carpio), and catfish (Pangasius hypothalmus).

The fishes were placed in a conical cage specially built in order to be not disturbed by the reflecting contribution of the lateral surface. The transducer is mounted in the center of the surface of the cage oriented downwards (Fig. 1). In this way, the transmitted signal is not attenuated by the net, the cage is sufficiently spacious to permit the movement of the fish and to record the echoes without interference. The cage was submerged down to the depth of about $5 \mathrm{~m}$. Measurements of acoustic descriptors value were done to five fishes per species and taken 2-3 days per species.

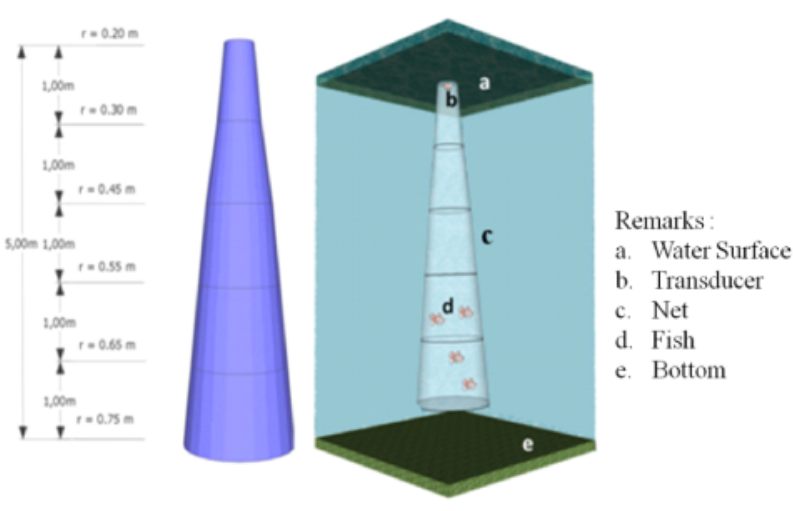

Figure1. Construction of net cage

\section{Acoustic Data Processing}

Acoustic data were post processed using Echoview Software version 4.8. Data shallower than $1 \mathrm{~m}$ were removed from analyses to eliminate the transmit pulse and reduce backscatter by surface bubbles. A background threshold of $-60 \mathrm{~dB}$ was applied equivalent to all echograms. The threshold was determined by analyzing a subset of data collected from the measurement and allowed accurate detection of target fishes. Echograms were visually inspected, and doubtful and 'false' detections (acoustic interference) were removed. For each detected acoustic target, a set of acoustic descriptors (Table 1), was calculated and extracted.

Table1. Acoustic descriptors and units used in the analysis

\begin{tabular}{lc}
\hline \multicolumn{1}{c}{ Acoustic Descriptor } & Unit \\
\hline Energetic & \\
Sv & $\mathrm{dB}$ \\
TS & $\mathrm{dB}$ \\
Area Backscattering Strength & $\mathrm{dB}$ \\
Skewness & \\
Kurtosis & \\
Morphological & \\
Height & $\mathrm{m}$ \\
Positional & \\
Depth & $\mathrm{m}$ \\
Relative altitude & $\mathrm{m}$ \\
\hline
\end{tabular}

\section{Data Analysis}

ANNs are mathematical models inspired by the human brain. They are able to recognize behavioral patterns and learn from their interactions with the environment. Back Propagation (BP) and multiple layer perceptrons (MLPs) neural network were constructed and computed using Matlab 6.0. Theyconsist of three feed-forward layers: input, hidden and output. The input layer was composed of eight variables. The number of nodes in the hidden layer was determined by testing the performance of the models using arrange of node numbers. The dependent variable fish groups represented the output layer. The data set was split into atraining set and validation set consisting of $70 \%$ and $30 \%$ of the identified shoals, respectively, with the same proportionof each fish group. Theneural network was trained by means of Scaled Conjugate Gradient Back propagation and Levenberg-Marquard learning algorithms in order to develop the ability to correctly classify fish shoals.

\section{RESULTS}

\section{Acoustic Descriptors}

The values of eight parameters extracted from acoustic data are presented in Tables 2, 3 and 4. 
Target strength (TS) of carp and tilapiashowed relatively same value at minimum fish sizes, but slightly higher for catfish as it has different body shape comparing to those the two species. In addition to fish size and body shape, The TS factors depends on some other aspects, such as swimbladder, the physiological state of the fish and its orientation (Ona, 1999). These aspects were reflected by great variation values of TS, Sv, and area backs cattering strength of the fishes as shown in the tables.

Table 2. The value of parameters of carp (Cyprinus carpio) extracted from acoustic data

\begin{tabular}{llrrrrrr}
\hline \multicolumn{1}{c}{ Decriptor } & Unit & Mininum & Maximum & Mean & $\begin{array}{c}\text { Std } \\
\text { error }\end{array}$ & $\begin{array}{c}\text { Std } \\
\text { deviation }\end{array}$ & Variance \\
\hline Sv & $\mathrm{dB}$ & -55.75 & -33.53 & -36.50 & 0.14 & 5.95 & 35.38 \\
TS & $\mathrm{dB}$ & -77.18 & -35.76 & -52.15 & 0.15 & 6.72 & 45.10 \\
Height & meter & 0.04 & 0.24 & 0.10 & 0.00 & 0.03 & 0.00 \\
Depth & meter & 0.26 & 4.35 & 1.42 & 0.02 & 0.86 & 0.74 \\
Rel_Altitude & meter & 35.69 & 83.60 & 40.34 & 0.04 & 1.96 & 3.83 \\
Backscattering strength & $\mathrm{dB}$ & -86.03 & -23.19 & -52.96 & 0.26 & 11.22 & 125.91 \\
Skewness & & -3.04 & 9.21 & 1.23 & 0.03 & 1.30 & 1.69 \\
Kurtosis & & -1.88 & 88.21 & 3.35 & 0.16 & 7.16 & 51.28 \\
N sample & 1910 & & & & & & \\
\hline
\end{tabular}

Table 3. The value of parameters of tilapia (Oreochromisniloticus) extracted from acoustic data

\begin{tabular}{llrrrrrr}
\hline \multicolumn{1}{c}{ Decriptors } & Unit & Mininum & Maximum & Mean & $\begin{array}{c}\text { Std } \\
\text { error }\end{array}$ & $\begin{array}{c}\text { Std } \\
\text { deviation }\end{array}$ & Variance \\
Sv & $\mathrm{dB}$ & -52.14 & -23.11 & -40.03 & 0.11 & 4.99 & 24.87 \\
TS & $\mathrm{dB}$ & -77.55 & -46.58 & -60.79 & 0.11 & 5.01 & 25.15 \\
Height & meter & 0.05 & 0.25 & 0.10 & 0.00 & 0.02 & 0.00 \\
Depth & meter & 0.47 & 4.51 & 2.76 & 0.02 & 1.04 & 1.09 \\
Rel_Altitude & meter & 35.49 & 43.14 & 38.59 & 0.03 & 1.48 & 2.18 \\
Backscattering strength & $\mathrm{dB}$ & -64.40 & -30.56 & -49.98 & 0.12 & 5.08 & 25.77 \\
Skewness & & -1.18 & 6.56 & 0.72 & 0.02 & 0.75 & 0.56 \\
Kurtosis & & -1.75 & 55.96 & 0.65 & 0.06 & 2.80 & 7.85 \\
N sample & 1910 & & & & & & \\
\hline
\end{tabular}

Table 4. The value of parameters of catfish (Pangasiushypothalmus)extracted from acoustic data

\begin{tabular}{llrrrrrr}
\hline \multicolumn{1}{c}{ Decriptors } & Unit & Mininum & Maximum & Mean & $\begin{array}{c}\text { Std } \\
\text { error }\end{array}$ & $\begin{array}{c}\text { Std } \\
\text { deviation }\end{array}$ & Variance \\
Sv & $\mathrm{dB}$ & -50.20 & -16.65 & -37.25 & 0.11 & 4.97 & 24.68 \\
TS & $\mathrm{dB}$ & -72.07 & -36.99 & -56.64 & 0.11 & 4.75 & 22.53 \\
Height & meter & 0.04 & 0.24 & 0.11 & 0.00 & 0.02 & 0.00 \\
Depth & meter & 0.30 & 4.49 & 2.22 & 0.02 & 0.94 & 0.89 \\
Rel_Altitude & meter & 36.58 & 42.55 & 39.47 & 0.02 & 0.94 & 0.89 \\
Backscattering strength & $\mathrm{dB}$ & -60.48 & -26.30 & -46.90 & 0.12 & 5.26 & 27.68 \\
Skewness & & -1.08 & 6.65 & 1.95 & 0.02 & 0.99 & 0.97 \\
Kurtosis & & -1.86 & 52.56 & 5.29 & 0.14 & 6.25 & 39.02 \\
N sample & 1910 & & & & & & \\
\hline
\end{tabular}




\section{Classification using Backpropagation (BP)ANN}

Pattern back-propagation ANN was used to recognize pattern as a vector form in the data matrix. Each pattern was given to the network and the output was compared with the response. The error function is calculated after all the patterns are presented. The optimization procedure (learning rule) was Scaled Conjugate Gradient Back propagation, which is a variation of steepest descent algorithm.

Pattern recognition of back-propagation ANN is two layers feed-forward with input and target in a binary form, activation function in the hidden layer and output using transig and biner. Trial and error was applied to determine the number of neuron that would produce highest accuracy in the classification.
Trial and error processes by using 1-100 neurons resulted the accuracy of more than $80 \%$, while those using 1 and 80 neurons gave the accuracy of $67.44 \%$ and $31.63 \%$, respectively. Lowest MSE was produced at 50 neurons (MSE $=0.0783$ ) with $15.58 \%$ error. By using input of 5730 pattern samples, the highest accuracy was found when the number of neuron in the hidden layer was 30 (Table 5).

As seen from Table 6, the use of 30 neurons in the hidden layer produced MSE of 0.0809 with $16.16 \%$ error at training phase, $0.0778 \%$ at validation phase and 0.0858 at testing phase with the errors of $16.16 \%$, $15.30 \%$, and $17.44 \%$, respectively.

Table 5. The MSE value and percentage of the error

\begin{tabular}{|c|c|c|c|c|c|}
\hline No & Training algorithm & Activation function & Neuron & MSE & $\% \mathrm{E}$ \\
\hline 1 & Scale Conjugate Gradient & trainscg & 1 & 0.1582 & 35.23 \\
\hline 2 & & & 10 & 0.0917 & 19.65 \\
\hline 3 & & & 20 & 0.0968 & 18.49 \\
\hline 4 & & & 30 & 0.0778 & 15.34 \\
\hline 5 & & & 40 & 0.0932 & 18.72 \\
\hline 6 & & & 50 & 0.0783 & 15.58 \\
\hline 7 & & & 60 & 0.1056 & 22.9 \\
\hline 8 & & & 70 & 0.0952 & 19.76 \\
\hline 9 & & & 80 & 0.2553 & 68.37 \\
\hline 10 & & & 90 & 0.0927 & 18.48 \\
\hline 11 & & & 100 & 0.0952 & 19.65 \\
\hline
\end{tabular}

Tabel 6. Results of the validation and testing

\begin{tabular}{lccl}
\hline & Sample & MSE & \% Error \\
\hline Training & 4010 & $8.09 \mathrm{E}-02$ & $1.62 \mathrm{E}+01$ \\
Validation & 860 & $7.78 \mathrm{E}-02$ & $1.53 \mathrm{E}+01$ \\
Testing & 860 & $8.59 \mathrm{E}-02$ & $1.74 \mathrm{E}+01$ \\
\hline
\end{tabular}

The accuracy of classification for three species of freshwater fish was presented in confusion matrix (Table 7), back-propagation (BP) ANN model gave the accuracy of $84.10 \%$ at the training phase $84.80 \%$ at the validation phase, and $82.60 \%$ during the testing. These results suggested that Back-propagation (BP) ANN model can be used for classification of three species of fresh water fish, directly from their acoustic data, giving the accuracy of prediction of $84.8 \%$.

\section{Classification using Multi Layer Perceptron (MLP) ANN}

Several different configurations of MLP were designed and trained, and we finally settled on a threelayer network with 8 input neurons, 3 hidden neurons and 1 output neuron. Learning rates was defined at 0.5 . In this work, Levenberg-Marquard algorithm was applied for calibration or learning method. The best MLP was selected as the one with the lowest error in the validation phase. The results are presented in Table 10.

At validation phase, MLP-ANN model gave the accuracy of $27.7 \%$ for carp, $27.8 \%$ for tilapia and $30.2 \%$ for catfish. A total of 85.7 percent of three species of fresh water fish was correctly classified (Table 8). 
Table 7. Confusion matrix for BP classification

\begin{tabular}{lcccc}
\hline & $\begin{array}{c}\text { Carp } \\
\text { \% Prediction }\end{array}$ & $\begin{array}{c}\text { Tilapia } \\
\text { \% Prediction }\end{array}$ & $\begin{array}{c}\text { Catfish } \\
\text { \% Prediction }\end{array}$ & $\begin{array}{c}\text { Total } \\
\text { \% Prediction }\end{array}$ \\
\hline Training & 28.10 & 27.60 & 28.40 & 84.10 \\
Validation & 27.10 & 26.00 & 31.60 & $\mathbf{8 4 . 8 0}$ \\
Testing & 29.00 & 25.90 & 27.70 & 82.60 \\
All & 28.10 & 27.10 & 28.80 & 84.00 \\
\hline
\end{tabular}

Tabel 8. Confusion matrix for MLP classification

Classification Results ${ }^{a}$

\begin{tabular}{|c|c|c|c|c|c|}
\hline & \multirow[t]{2}{*}{ Fish code } & \multicolumn{3}{|c|}{ Predicted Group Membership } & \multirow{2}{*}{ Total } \\
\hline & & Carp & Tilapia & Catfish & \\
\hline \multirow[t]{3}{*}{ Count } & Carp & 1587 & & & 1910 \\
\hline & Tilapia & & 1595 & & 1910 \\
\hline & Catfish & & & 1730 & 1910 \\
\hline \multirow[t]{3}{*}{$\%$} & Carp & 27.7 & & & 86.9 \\
\hline & Tilapia & & 27.8 & & 84.9 \\
\hline & Catfish & & & 30.2 & 85.4 \\
\hline
\end{tabular}

a. $\mathbf{8 5 . 7 \%}$ of original grouped cases correctly classified.

\section{DISCUSSION}

The TS of an individual fish depends on the sound frequency, as well as on some fish characteristics such as size, anatomy, physiology and swimming behavior. It is suggested that environmental factors cause different morphological adaptations within species (Fassler et al., 2008) and consequentially backscattering properties.

As is well known, the backscattering energy from the swimming fish is a dynamic quantity, highly dependent on fish behavior, particularly the swim tilt angle (Huse \& Ona, 1996). The different behavior is also responsible for the measured systematic differences inestimated mean TS values. The validity of this finding was proved for all three target species. This phenomenon was well known from cage experiments (Simmonds \& MacLennan, 2005).

As the modelling techniques have widely available, researchers have a lot of methods ranging from numerical, mathematical and statistical methodsto techniques based on artificial intelligence, particularly ANNs. The choice of the type of network depends on the nature of the problem to be solved. At present, the popular ANNs are multi-layer feed-forward neural networks trained by back propagation algorithm, i.e. back propagation network (BPN). The BPN is most often used, but other networks has also gained popularity.
Ramani \& Patrick (1992), Haralabous \& Georgakarakos (1996), Simmonds et al. (1996), and Lawson et al. (2001) have applied ANNs for fishspecies identification under different conditions, i.e. fish captive in tanks and in the wild and using different input signals to train the ANNs for fish-species classification. Haralabous and Georgakarakos (1996) used the same approach asthat employed here: acoustic descriptors as the input for the ANNs.

Results of the analysis showed that the difference between back propagation (BP)-ANN and MLP was more important for tilapia and catfish, while for carp both model sprovided relatively similar classification level. However, Tables 9 and 10 show that MLP perform better than back propagation (BP) in fish classification. It is likely that MLP is more robust than MLPs and is thus more suitable for dealing with the noise inherent in the training examples of fish shoals.

\section{CONCLUSION}

Performance of the models is obtained from the analysis: $85.7 \%$ of three species of freshwater fish is correctly classified by the MLP, $84.8 \%$ of these three species is correctly classified by back propagation (BP). This suggested that MLP perform better than back propagation (BP) in fish classification. The difference between back propagation (BP)-ANN and MLP was more important for tilapia and catfish, while for carp both models provided relatively similar classification level. 
For fish classification using ANNs, the training data have to be constantly updated. This will lead to better classification results for the three species studied, and the addition of other species to the training set. The results of future surveys are necessary before any definitive classification method can be achieved.

\section{REFERENCES}

Charef, A., S. Ohshimo, I. Aoki, N.A. Absi. 2010. Classification Of Fish Schools Based On Evaluation Of Acoustic Descriptor Characteristics. Fish Sci. 76:1-11.

Diner, N., Weill, A., Coail, J.Y., \& Coudevil, J.M. 1989. "Ines-Movies": A New Acoustic Data Acquisition and Processing System. ICES Journal of Marine Science, 45:255-267.

Fassler, S.M.M.; Gorska, N.; Ona, E. \& Fernandes, P.G. 2008. Differences in swim bladder volume between Baltic and Norwegian spring-spawning herring: consequences for mean target strength. Fisheries Research, 92: 314-321.

Fauziyah. 2005. Identifikasi, Klasifikasi dan Analisis Struktur Spesies Kawanan Ikan Pelagis berdasarkan Metode Deskriptor Akustik. Disertasi (tidak dipublikasikan). Program Pasca sarjana IPB. Bogor. $178 \mathrm{p}$.

Georgakarakos, S., \& Paterakis, O.A. 1993. "School": A Software for Fish School Identification. ICES Journal of Marine Science, 8:94-108.

Haralabous, J., Georgakarakos, S., 1996. Artificial neural networks as a tool forspecies identification of fish schools, Fisheries-and-Plankton-Acoustics. In: Simmonds, E.J., Maclennan, D.N. (Eds.), Proceedings of an ICES International Symposium, vol. 53. Aberdeen, Scotland, 12-16 June 1995. Academic Press, London, UK, p. 173-180.
Huse, I., \& Ona, E. 1996. Tilt angle distribution and swimming speed of over wintering Norwegian spring spawning herring. ICES Journal of Marine Science, 53: 863-873.

Jech, J.M., Michaels, W.L. 2006. A multi frequency method to classify and evaluate fisheries acoustics data. Can J Fish Aquat Sci 63: 2225-2235.

Lawrence, 1992. Introduction to Neural Networks and Expert System. California Scientific Software. 264 p.

Muhiddin, A.M., 2007. Permodelan Jaringan Saraf Tiruan (Artificial Neural Networks) Untuk Identifikasi Kawanan Lemuru Dengan Menggunakan Deskriptor Akustik. Disertasi (tidak dipublikasikan). Program Pascasarjana IPB. Bogor. 165 p.

Ona, E., 1999. Methodology for target strength measurements. ICES Coop. Res. Rep.235: 59 p.

Ramani, N.,\& Patrick, P.H., 1992. Fish detection and identification using neural networks-some laboratory results. IEEE J. Ocean. Eng. 17, 364368.

Robotham, A., Bosch, P., Estrada, J.C.G., Castilla, J., Calvo, I.P., 2010. Acoustic Identification of small pelagic fish species in Chile using support vector machines and neural networks. Fisheries Research. 102:115-122.

Simmonds, E.J., Armstrong, F., Copland, P.J., 1996. Species identification using wide band backscatter with neural network and discriminant analysis. ICES J. Marine Sci. 53, 189-195.

Simmonds J, \& MacLennan D., 2005. Fisheries acoustics: theoryand practice, 2nd edition. Blackwell, Oxford. 437 p. 